\title{
Pathogenicity of indigenous strains of three entomopathogenic fungi to the sisal weevil, Scyphophorus acupunctatus (Gyllenhal) (Coleoptera: Curculionidae)
}

\author{
V.T. Gkounti, D. Markoyiannaki and D.Ch. Kontodimas*
}

Summary The pathogenicity of indigenous isolates of Beauveria bassiana, Metarhizium anisopliae and Isaria fumosorosea was evaluated in the laboratory against larvae and adults of the sisal weevil, Scyphophorus acupunctatus. Inoculation was achieved via immersion of individuals into conidia suspensions of different concentrations. All three fungal species proved high pathogenicity against larvae of the weevil, causing $100 \%$ mortality in most of the treatments. Beauveria bassiana caused the highest mortality of the adults $(86.67 \pm 12 \%)$, followed by M. anisopliae $(46.67 \pm 17.8 \%)$ and I. fumosorosea $(40 \pm 17.5 \%)$. Mean survival time also differed significantly among treatments and life stages of the weevil. In total, larvae survived significantly fewer days than adults post infection. Results of the present study indicate the potential of indigenous strains of entomopathogenic fungi as biological control agents against the invasive weevil.

Additional keywords: agave, Beauveria bassiana, Curculionidae, Isaria fumosorosea, Metarhizium anisopliae

\section{Introduction}

The sisal weevil, Scyphophorus acupunctatus (Gyllenhal), is amongst the most severe pests of both cultivated and ornamental agave plants (Pott, 1975; Valenzuela-Zapata, 1994; Camino Lavin et al., 2002). In its place of origin, the Nearctic region, it has been found to cause severe economic losses by strongly damaging Agave tequilana (Weber) the tequila producing agave (Solis et al., 2001). The sisal weevil was introduced in Europe around 1980, when it was first recorded on imported Yucca sp. in the Netherlands (van Rossem et al., 1981). Since then it has been found in many European countries (i.e. Italy, France, Greece) on ornamental plants (Colombo, 2000; EPPO 2008; Kontodimas and Kallinikou, 2010).

The females use the basal parts of the agave leaves for feeding and as oviposition sites. Furthermore, once the neonate larvae hatch they start to bore galleries within the plant's head and form a cocoon made

Department of Entomology and Agricultural Zoology, Benaki Phytopathological Institute, 8 St. Delta Str., GR-145 61 Kifissia, Attica, Greece

* Corresponding author: d.kontodimas@bpi.gr by plant's fibers to complete their development (Lock, 1965). In addition to the destructive activities of the larvae, the adults are often natural vectors of plant pathogenic bacteria, such as Erwinia carotovora (Dye) (Aquino Bolanos et al., 2011). In Central and South American agave cultivations chemical insecticides are commonly applied to control the sisal weevil, however there are many problems and controversies connected to their use (Solis et al., 2001; Terán-Vargas et al, 2012). Firstly, as the weevil completes its development within a protected habitat, inside the agave leaves, insecticides have a low effectiveness (Figueroa-Castro et al., 2013). Secondly, their extended application harbors the risk of resistance development in the pest species (Terán -Vargas et al., 2012). Finally, there are certain restrictions in the use of synthetic insecticides in urban landscape areas, where the weevil is mainly found, due to their effects on the environment and health risks. Therefore, the development of biological and biotechnical control methods is of great environmental and economic importance.

Although a few arthropod natural enemies of the sisal weevil could potentially be regarded as biological control agents in its 
site of origin (Velazquez et al., 2008), these arthropods are not found in the invaded regions. Entomopathogenic fungi and nematodes have been reported as potential biological control agents of the weevil (Hueso et al., 2005; Velazquez et al., 2008). Both the fungi and the nematodes are of great importance for the biological control of S. acupunctatus, as they are able to overcome the barrier of the concealed environment in which the weevil develops. While the nematodes are able to move within the agave leaves and are easily able to reach the concealed pest (Dembilio et al., 2010a), the entomopathogenic fungi infect their hosts by direct contact and subsequent penetration of their cuticle (Dembilio et al., 2010b). This makes insects susceptible both to direct contact with the pathogen, but also to passive, horizontal transmission, between healthy and infected individuals vectoring spores (Klein and Lacey, 1999; QuesadaMoraga et al., 2004).

It has been widely accepted that entomopathogenic fungi show high intra-specific diversity, which results in different levels of pathogenicity among different strains of the same species (Ferron, 1978). Furthermore, the virulence of a specific strain to specific insect genera has been proved to depend upon the host insect identity from which it was isolated (Fargues and Robert, 1983; Maurer et al., 1997). This is attributed to the strong selective pressure of the host insect environment on the pathogen (Roy et al., 2006) through which the origin of the entomopathogens could affect their pathogenicity against pests (Cherry et al., 2005).

Despite the importance of alternative methods for the control of the sisal weevil, research on the evaluation of potential biological control agents of the pest is very limited (Molina-Ochoa et al., 2004; Valdes Estrada et al., 2014). In the present study we aim to evaluate the virulence of locally isolated strains of Beauveria bassiana (Balsamo), Metarhizium anisopliae (Metchnikoff) Sorokin and Isaria fumosorosea (Wize) to adults and larvae of the introduced weevil S. acupunctatus. It is expected that the use of in- digenous isolates of fungal entomopathogens is advantageous, as they are already adapted in specific environmental conditions and could be part of a conservation biological control strategy.

\section{Material and Methods}

\section{Entomopathogenic fungi}

All entomopathogenic fungi strains used in the laboratory assays were obtained from the entomopathogenic fungi collection of the Benaki Phytopathological Institute. The strain of B. bassiana IBB 010 was initially isolated from a Rhynchophorus ferrugineus (Olivier) cadaver, found in Ellinikon region (Athens, Greece). Both strains IBB020 of I. fumosorosea and TMB04 of M. anisopliae were isolated from soil samples with the Galleria bait method (Zimmerman, 1986) from the Agios Stefanos and Marathon regions (Attica, Greece), respectively. The molecular identification of the strains of I. fumosorosea and $M$. anisopliae was previously conducted by Beris et al. (2013). The fungal isolations were cultured on Sabouraud dextrose agar (SDA) at $25^{\circ} \mathrm{C}$, under dark regulated conditions. Spore (conidia) suspensions were prepared by scraping the surface of 2 week old cultures into an aqueous solution of $0.2 \%$ Tween 80, after which the suspensions were vortexed for $60 \mathrm{~s}$ and filtered twice using a sterile nylon membrane to remove mycelium. Subsequently, the concentration of the spore suspensions was determined by the use of a standard haemocytometer. The concentrations of spore suspensions used in bioassays were $2.12 \times 10^{7}$ and $2.12 \times 10^{6}$ spores/ml for B. bassiana, $1.27 \times 10^{7}$ and 1.27 x $10^{6}$ spores $/ \mathrm{ml}$ for M. anisopliae and $7.45 \mathrm{x}$ $10^{6} \mathrm{spores} / \mathrm{ml}$ for $I$. fumosorosea. Spore concentrations are not equal due to the different developmental rate of each fungus (Kontodimas and Gkotsi, 2009). Spore viability measured over $96 \%$ for all selected strains.

\section{Insects}

Both adult and larvae of the sisal weevil were collected from ornamental aga- 
ve plants, Agave americana L., in the urban landscape area of Ardittos hill (Athens, Greece). The infestation of the agave plants was spotted in the summer of 2012 and no action for controlling the pest was taken prior to the collection of the weevils. The adults were collected by hand at site, while whole plants were cut from the basis and taken to the laboratory for the isolation of $4^{\text {th }}$ instar larvae. The adults were kept in polyester cages $(30 \times 30 \times 30 \mathrm{~cm})$ and the larvae in plastic boxes $(20 \times 20 \times 20 \mathrm{~cm})$, with an opening covered by mesh for ventilation. All insects were kept at controlled laboratory conditions $\left(25 \pm 1^{\circ} \mathrm{C}, 65 \pm 5 \%\right.$ R.H. and 14:10 L:D) and fed on a natural diet (agave slices; twice per week) until they were used in the bioassays.

\section{Bioassays}

The application of the spore suspensions was achieved through direct cuticle contact. Groups of five, $4^{\text {th }}$ instar larvae and adults were immersed in the prepared aqueous suspensions for $30 \mathrm{sec}$ after which each group of insects was transferred in $1 \mathrm{~L}$ rearing boxes and provided with fresh natural diet. The treatment was repeated 15 times (replicates) for each fungus strain and concentration per life stage. Furthermore, a control treatment was included for both adults and larvae, where insects were immersed into an aqueous solution of $0.2 \%$ Tween 80 . All bioassays were carried out in controlled environment conditions $\left(25 \pm 1^{\circ} \mathrm{C}, 65 \pm 5 \%\right.$ R.H. and 14:10 L:D). The mortality was recorded daily for up to 11 and 21 days for larvae and adults, respectively. When a weevil died, the cadaver was transferred individually to a Petri dish lined with a moistened sterile filter paper to ascertain the involvement of the entomopathogens to the death of weevils. The Petri dishes were sealed with parafilm and kept at room temperature, in darkness, to monitor for external signs of fungal infection.

\section{Statistical analyses}

General Linear Model (GLM) with a binomial distribution was used to obtain Analysis of Deviance for a level of significance $a=0.05$. The analysis included life stage (larval and adult), species of fungi (B. bassiana, I. fumosorosea and M. anisopliae), and concentration of spore suspensions $\left(10^{6}\right.$ and $10^{7}$ spores $/ \mathrm{ml}$ ) as variables. Additionally, the average survival times were calculated and compared by the Kaplan-Meier survival analysis (Kaplan and Meier, 1958). All the GLM procedures and survival analysis were carried out in R (v. 2.1; R Foundation for Statistical Computing, Vienna, AT).

\section{Results}

The examined strains of entomopathogenic fungi caused different levels of mortality to S. acupunctatus. The mean mortality of weevils differed significantly at different life stages, and fungus species, but it did not differ between different concentrations of spore suspensions $\left(X^{2}=22.939, \quad d f=1, \quad P<0.0001\right.$; $X^{2}=9.5758, d f=2, P<0.0001$ and $X^{2}=2.5984$, $d f=1, P=0.1070$, respectively). No mortality was recorded for adult weevils or larvae when treated with the aqueous solution of $0.2 \%$ Tween 80 (i.e. control treatment). Interactions among the variables did not affect the mortality levels, thus, they were omitted from the initial model.

All treatments with fungi resulted in almost all concentrations at $100 \%$ mortality of larvae (Figure 1a). Mortality in adults depended on fungus species but not on the concentration of the suspensions $\left(X^{2}=11.4223, d f=2\right.$, $P=0.0033$ and $X^{2}=2.9638, d f=1, P=0.0851$, respectively). The treatment with $B$. bassiana at the concentration of $2.12 \times 10^{7}$ spores $/ \mathrm{ml}$ caused the highest mortality to adult weevils $(86.67 \pm 12 \%)$ compared to $M$. anisopliae and $I$. fumosorosea treatments (Figure 1b). The lowest mortality levels to adults were caused by M. anisopliae, when applied the low spore concentration (26.67 $\pm 15.8 \%)$.

The examined strains of $B$. bassiana, $M$. anisopliae and I. fumosorosea developed external fungal growth and sporulated on all treated cadavers of both adults (Figure 2) and larvae, regardless the spore concentration. 


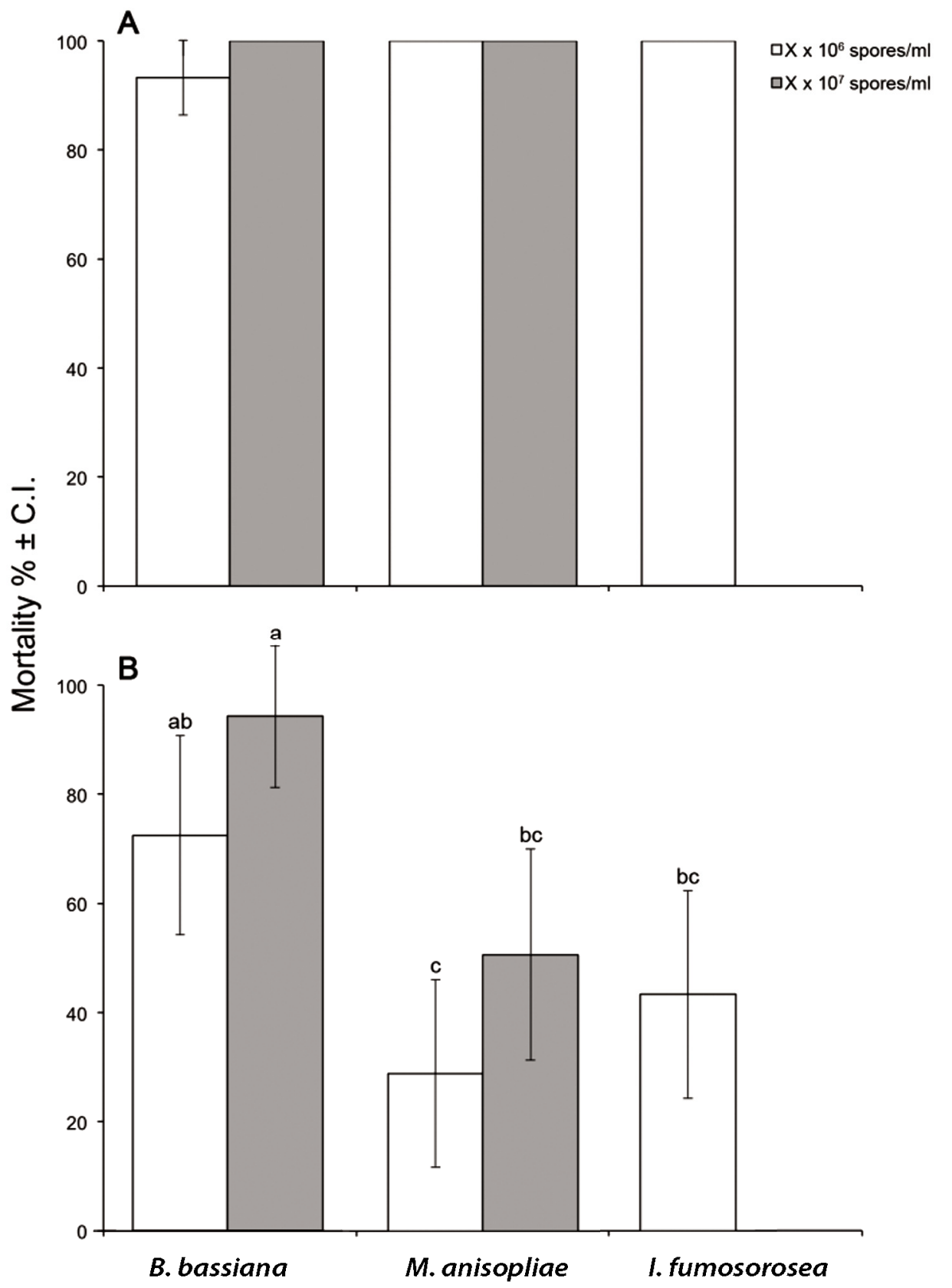

Figure 1. Mean mortality \pm SE of (A) larvae and (B) adults of Scyphophorus acupunctatus after immersion into spore suspensions of entomopathogenic fungi.

*Different letters within the same chart indicate significant differences ( $L R$ test, $a=0.05$ ). 

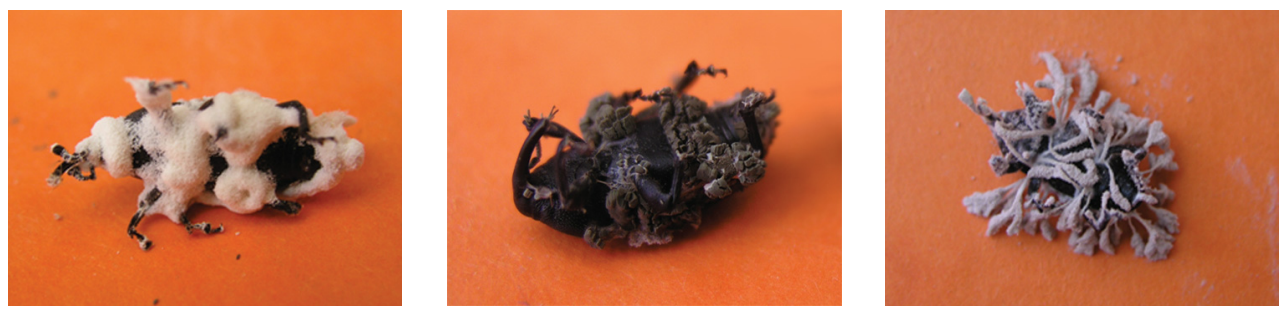

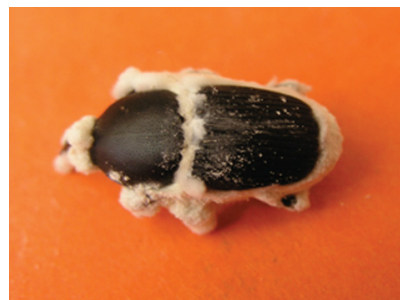

(a)

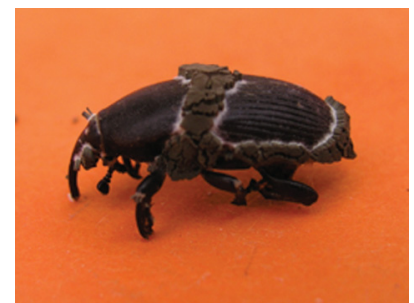

(b)

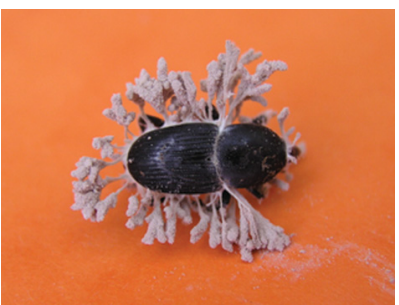

(c)

Figure 2. Development of external fungal mycelium on cadavers of Scyphophorus acupunctatus adults: Beauveria bassiana (a), Metarhizium anisopliae (b) and Isaria fumosorosea (c).

The mean survival time of the treated larvae differed significantly at different fungi species and different concentrations, namely the low concentration of $B$. bassiana (6.80 \pm 0.251 days) compared to the other treatments (4.73-5.67 days) $\left(X^{2}=8.3, d f=4\right.$, $P=0.0807$; Table 1 ).

The mean survival time differed significantly for adult weevils that received different treatments $\left(X^{2}=17.5, d f=4, P=0.0016\right.$; Table 1). Adult weevils treated with the high concentration of $B$. bassiana exhibited the shortest survival time (10.20 \pm 1.055 days) (Table 1). Overall, the survival time of larvae was significantly shorter than that of adults $\left(X^{2}=105, d f=1, P<0.001\right)$.

\section{Discussion}

All species of fungi proved to be highly effective on larvae of $S$. acupunctatus. Further wider dose range tests would be necessary to show the dose effect, the differences among strains and the potential of the tested strains in lower concentrations. However, our results showed that the examined strains of entomopathogenic fungi are able to infect larvae and adults of the sisal wee- vil. Although all strains managed to fully complete their life cycle by sporulating on S. acupunctatus cadavers, B. bassiana proved to be the most pathogenetic to adult weevils. Several studies have pointed out the relation between strains of entomopathogens isolated from specific hosts and the high virulence towards the host genera (Fargues and Robert, 1983; Maurer et al., 1997). Therefore, the high virulence of the strain IBB010 of $B$. bassiana might be related to its source of isolation, an infected red palm weevil cadaver, as both the red palm weevil and the sisal weevil belong to the same tribe of Rhynchophorini.

Until now, B. bassiana is the only entomopathogenic fungus species mentioned as a natural enemy of the weevil in its place of origin (Aquino Bolanos et al., 2011). Our results showed that the concentration of 2.12 $x 10^{7}$ spore suspension of $B$. bassiana caused a quicker death of adults compared to spore suspensions of $M$. anisopliae and I. fumosorosea. Moreover, a 10-fold increase of the diluted spore suspension of the $B$. bassiana strain from $2.12 \times 10^{6}$ to $2.12 \times 10^{7}$ decreased the mean survival time for adults by almost 4 days .

The sisal weevil has identical life hab- 
Table 1. Mean survival time \pm SE (days after treatment) for larvae and adults of Scyphophorus acupunctatus treated with Beauveria bassiana, Metarhizium anisopliae and Isaria fumosorosea spore suspensions.

\begin{tabular}{l|c|c|c}
\hline \multirow{2}{*}{ Treatment } & \multirow{2}{*}{ Concentration (spores $/ \mathrm{ml}$ ) } & \multicolumn{2}{|c}{ Mean survival time \pm SE (days) } \\
\cline { 2 - 4 } & $2.12 \times 10^{7}$ & Larvae & Adults \\
\hline B. bassiana & $2.12 \times 10^{6}$ & $5.47 \pm 0.351^{\mathrm{a}}$ & $10.20 \pm 1.055^{\mathrm{a}}$ \\
& $1.27 \times 10^{7}$ & $6.80 \pm 0.251^{\mathrm{b}}$ & $14.74 \pm 0.999^{\mathrm{b}}$ \\
M. anisopliae & $1.27 \times 10^{6}$ & $5.00 \pm 0.359^{\mathrm{a}}$ & $15.65 \pm 1.031^{\mathrm{bc}}$ \\
I. fumosorosea & $7.45 \times 10^{6}$ & $5.67 \pm 0.308^{\mathrm{ab}}$ & $17.20 \pm 1.210^{\mathrm{c}}$ \\
\hline
\end{tabular}

* Mean survival times within columns followed by the same letter are not significantly different (LR test, $a=0.05$ )

* Mortality was recorded for up to 11 and 21 days for larvae and adults, respectively

its with the red palm weevil and its development is completed within its host plant, adults are the only exposed stage to entomopathogenic fungal treatments (Gindin et al., 2006; Dembilio et al., 2010b). Therefore, the longer survival of an infected host increases the possibility of interacting with other individuals and probably of transmitting the pathogen. In this sense, a lower spore concentration of B.bassiana might be more advantageous in a field application, especially because our study showed that the mean mortality did not differ significantly between the two concentrations. However, other aspects of the application of these entomopathogenic fungi are not yet fully studied. For example, potential horizontal transmission between adults or from adults to larvae and vertical transmission from infected adults to their offspring should be elucidated (Glare et al., 2002; Gindin et al., 2006; Dembilio et al., 2010b). Furthermore, M.anisopliae and B. bassiana have been found to reduce the fecundity of $R$. ferrugineus (Gindin et al., 2006; Dembilio et al., 2010b). If a similar effect can be proved on $S$. acupunctatus, then even strains that caused lower levels of mortality might be a useful tool in the control of the weevil.

Another important finding of the present study is the high mortality of larvae caused by all the strains tested. In most of the cases, mortality in the larval stage reached $100 \%$. Although our methodology of immersing the larvae differs considerably from the natural infection, such high mortality levels in controlled conditions support these strains as candidate biological control agents. While the larvae of the weevil are the most destructive stage they are also the most concealed life stage (Camino Lavin et al., 2002; Lopez-Martinez et al., 2011), challenging the application of the entomopathogenic fungi. It is, however, possible that entomopathogenic fungal endophytes are effective against larval stages of the weevil. Among many others, the entomopathogenic fungi B. bassiana, M. anisopliae and $I$. fumosorosea have been reported as endophytes of several plants (Gomez-Vidal et al., 2006; Quesada-Moraga et al., 2006; Vega, 2008) and attempts have been made to introduce entomopathogens into host plants for the control of pests (Gomez-Vidal et al., 2006, Posada et al., 2007; Valdes Estrada et al., 2014). If the strains studied here could be introduced into agave plants they could possibly act as successful biocontrol agents due to their high pathogenicity against larvae.

In conclusion, our results prove that the strain IBB 010 of B. bassiana is highly pathogenic to both adults and larvae of $S$. acupunctatus and could be considered as a biological control agent of the weevil. Additionally, application of lower concentrations of IBB 010 was shown to prolong the adults' survival time, without reducing the mortality levels. This should be taken into consideration, as a positive effect for strategies 
based on attracting and infecting adults. Strains IBB020 and TMB04 of I. fumosorosea and $M$. anisopliae, respectively, caused lower mortality levels to adults, but were equally effective on larvae. Hence, they could be considered as potential control agents into an IPM plan against the pest.

Despite the lack of field data on the effectiveness of these strains, to the best of our knowledge, this is the first attempt of screening locally isolated entomopathogenic fungi as biological control agents against the introduced S. acupuntatus. Further research in field applications and possibility of transmission is needed in order to strengthen current findings.

\section{Literature Cited}

Aquino Bolanos, T., Ruiz Vega, J., Giron Pablo, S., Perez Pacheco, R., Martinez Tomas, S.H. and Silva Rivera, M.E. 2011. Interrelationships of the agave weevil Scyphophorus acupunctatus (Gyllenhal), Erwinia carotovora (Dye), entomopathogenic agents and agrochemicals. African Journal of Biotechnology, 10: 15402-15406.

Beris, E.I., Papachristos, D.P., Fytrou, A., Antonatos, S.A. and Kontodimas, D.C. 2013. Pathogenicity of three entomopathogenic fungi on pupae and adults of the Mediterranean fruit fly, Ceratitis capitata (Diptera: Tephritidae). Journal of Pest Science, 86: 275-284.

Camino Lavin, M., Castrejon Gomez, V.R., Figueroa Brito, R., Aldana Llanos, L. and Valdes Estrada, M.E. 2002. Scyphophorus acupunctatus (Coleoptera: Curculionidae) attacking Polianthes tuberosa (Liliales: Agavaceae) in Morelos, Mexico. Florida Entomologist, 85: 392-393.

Cherry, A.J., Abalo, P. and Hell, K. 2005. A laboratory assessment of the potential of different strains of the entomopathogenic fungi Beauveria bassiana (Balsamo) Vuillemin and Metarhizium anisopliae (Metschnikoff) to control Callosobruchus maculatus (F.) (Coleoptera: Bruchidae) in stored cowpea. Journal of Stored Product Research, 41: 295-309.

Colombo, M. 2000. First record of Scyphophorus acupunctatus (Coleoptera Curculionidae) in Italy. Bollettino di Zoologia Agraria e di Bachicoltura, 32: 165-170.

Dembilio Ó., Llácer E., Martínez de Altube, M. and Jacas, J.A. 2010a. Field efficacy of imidacloprid and Steinernema carpocapsae in a chitosan formulation against the red palm weevil Rhynchophorus ferrugineus (Coleoptera: Curculion- idae) in Phoenix canariensis. Pest Management Science, 66: 365-370.

Dembilio O., Quesada-Moraga E., Santiago-Alvaro C. and Jacas J.A. 2010b. Potential of an indigenous strain of the entomopathogenic fungus Beauveria bassiana as a biological control agent against the red palm weevil, Rhynchophorus ferrugineus. Journal of Invertebrate Pathology, 104: 214-221.

EPPO. 2008: First record of Scyphophorus acupunctatus in France. EPPO Reporting Service 2008/220.

Fargues, J.F. and Robert, P.H. 1983. Effects of passing through scarabeid hosts on virulence and host specificity of two strains of the entomopathogenic hyphomycete Metarhizium anisopliae. Canadian Journal of Microbiology, 29: 576-583.

Ferron, P. 1978: Biological control of insect pests by entomogenous fungi. Annual Review of Entomology, 23: 409-442.

Figueroa-Castro, P., Solís-Aguilar, J.F., GonzálezHernández, H., Rubio-Cortés, R., Herrera-Navarro, E.G., Castillo-Márquez, L.E. and Rojas, J.C. 2013. Population dynamics of Scyphophorus acupunctatus (Coleoptera: Curculionidae) on blue agave. Florida Entomologist, 96: 1454-1462.

Gindin, G., Levski, S., Glazer, I. and Soroker, V. 2006. Evaluation of the entomopathogenic fungi Metarhizium anisopliae and Beauveria bassiana against the red palm weevil Rhynchophorus ferrugineus. Phytoparasitica, 34: 370-379.

Glare, T.R., Placet, C., Nelson, T.L. and Reay, S.D. 2002. Potential of Beauveria and Metarhizium as control agents of pinhole borers (Platypus spp.). New Zealand Plant Protection, 55: 73-79.

Gomez-Vidal, S., Lopez-Llorca, L.V., Jansson, H.-B. and Salinas, J. 2006. Endophytic colonization of date palm (Phoenix dactylifera L.) leaves by entomopathogenic fungi. Micron, 37: 624-632.

Hueso, E.J., Molina-Ochoa, J., Fallad-Chávez, J., Lezama-Gutiérrez, R.R., López-Edwards, M. and Farías-Larios, J. 2005. Susceptibility of Scyphophorus acupunctatus Gyllenhal (Coleoptera: Curculionidae) larvae to entomopathogenic nematodes Steinernema (Rhabditida: Steinernematidae). HortScience, 40: 1025-1025.

Kaplan, E.L. and Meier, P. 1958. Nonparametric estimation from incomplete observations. Journal of the American Statistical Association, 53: 457481.

Klein, M.G. and Lacey, L.A. 1999. An attractant trap for autodissemination of entomopathogenic fungi into populations of the japanese beetle Popillia japonica (Coleoptera: Scarabaeidae). Biocontrol Science and Technology, 9: 151-158.

Kontodimas, D.C. and Gkotsi, T. 2009. Non-linear temperature dependent development of the entomopathogenic fungi Beauveria bassiana, Paecilomyces fumosoroseus and Metarhizium anisopliae. $13^{\text {th }}$ Panhellenic Entomological Con- 
gress, Alexandroupolis Nov 3-6, 2009: 284-287.

Kontodimas, D.C. and Kallinikou, E. 2010. First record of the sisal weevil Scyphophorus acupunctatus (Coleoptera: Curculionidae) in Greece. Entomologia Hellenica, 19: 39-41.

Lock, G.W. 1965. Sisal; thirty years sisal research in Tanzania. Tanganyika Sisal Growers Association ( $2^{\text {nd }}$ edition). Longmans, London, pp. 1-365.

Lopez-Martinez, V., Alia-Tejacal, I., Andrade-Rodríguez, M., de Jesús García-Ramírez, M. and Rojas, J.C. 2011. Daily activity of Scyphophorus acupunctatus (Coleoptera: Curculionidae) monitored with pheromone-baited traps in a field of mexican tuberose. Florida Entomologist, 94: 1091-1093.

Maurer, P., Couteaudier, Y., Girard, P.A., Bridge, P.D. and Riba, G. 1997. Genetic diversity of Beauveria bassiana and relatedness to host insect range. Mycological Research, 101: 159-164.

Molina-Ochoa, J., Hueso-Guerrero, E.J., LezamaGutiérrez, R.R., Farías-Larios, J., Radillo-Juárez, F., García-Berbe, A. and Fallad-Chávez, J. 2004. Virulence of native and exotic entomopathogenic nematodes (Rhabditida: Steinerematidae, Heterorhabditidae) against larvae of the agave weevil, Scyphophorus acupunctatus (Coleoptera: Curculionidae). HortScience, 39: 832-832.

Posada, F., Aime, M.C., Peterson, S.W., Rehner, S.A. and Vega, F.E. 2007. Inoculation of coffee plants with the fungal entomopahtogen Beauveria bassiana (Ascomycota: Hypocreales). Mycological Research, 111: 748-757.

Pott, J.N. 1975. A yucca borer Scyphophorus acupunctatus in Florida. Proceedings of the Florida State Horticultural Society, pp. 414-416.

Quesada-Moraga, E., Landa, B.B., Muñoz-Ledesma, J., Jiménez-Diáz, R.M. and Santiago-Alvarez, C. 2006. Endophytic colonisation of opium poppy, Papaver somniferum, by an entomopathogenic Beauveria bassiana strain. Mycopathologia, 161: 323-329.

Quesada-Moraga, E., Santos-Quirós, R., ValverdeGarcía, P. and Santiago-Alvarez, C. 2004. Virulence, horizontal transmission, and sublethal reproductive effects of Metarhizium anisopliae (Anamorphic fungi) on the German cockroach (Blattodea: Blattellidae). Journal of Invertebrate Pathology, 87: 51-58.

Roy, H.E., Steinkraus, D.C., Eilenberg, J., Hajek, A.E. and Pell, J.K. 2006. Bizzare interactions and endgames: entomopathogenic fungi and their arthropod hosts. Annual Review of Entomology, 51: 331-357.
Solis, A.J.F., Gonzalez, H., Leyva, V.J.L., Equiuia, M.A., Flores, M.F.J. and Martinez, G.A. 2001. Scyphophorus acupunctatus Gyllenhal plaga del agave tequilero en Jalisco, México. Agrociencia, 35: 663-670.

Terán-Vargas, A.P., Azuara-Domínguez, A., VegaAquino, P., Zambrano-Gutiérrez, J. and Blanco-Montero, C. 2012. Biological effectivity of insecticides to control the agave weevil, Scyphophorus acupunctatus Gyllenhal (Coleoptera: Curculionidae), in Mexico. Southwestern Entomologist, 37: 47-53.

Valdes Estrada, M.E., Aldana Llanos, L., Hernandez Reyes, M.C., Gutierrez Ochoa, M., and Figueroa Brito, R. 2014. Toxicity of vegetable powders on Scyphophorus acupunctatus Gyllenhal (Coleoptera: Curculionidae) larvae. Southwestern Entomologist, 39: 595-599.

Valenzuela-Zapata, A.G. 1994. Los agaves tequileros. Boletin Amaranto, 7: 1-8.

van Lenteren, J.C., Bale, J., Bigler, F., Hokkanen, H.M.T. and Loomans, A.J.M. 2006. Asessing risk of releasing exotic biological control agents of arthropod pests. Annual Review of Entomology, 51: 609-634.

van Rossem, G., van de Bund, C.F., Burger, H.C. and de Goffau, L.J.W. 1981. Notable infestations by insects in 1980. Entomologische Berichten, 41: 84-87 (in Dutch, English abstr.).

Vega, F.E. 2008. Insect pathology and fungal endophytes. Journal of Invertebrate Pathology, 98: 277-279.

Velazquez, J., Joly, L.J., García, J.L., Romero, Y., González, M., and Medina, M. 2008. Enemigos naturales del picudo del agave Scyphophorus acupunctatus Gyllenhal (Coleoptera: Curculionidae) en el estado Falcón, Venezuela. Entomotropica, 21: 185-193.

Zimmermann, G. 1986. The Galleria bait method for detection of entomopathogenic fungi in soil. Journal of Applied Entomology, 102: 213-215.

Received: 22 April 2015; Accepted: 31 May 2015 


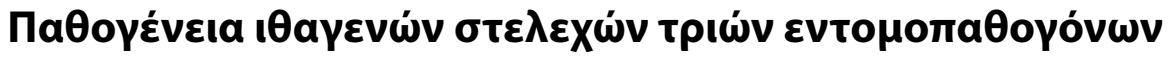

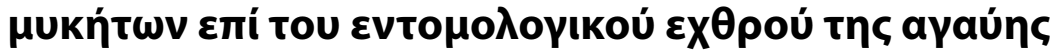 Scyphophorus acupunctatus (Gyllenhal) (Coleoptera: Curculionidae)
}

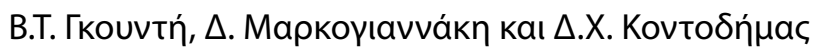

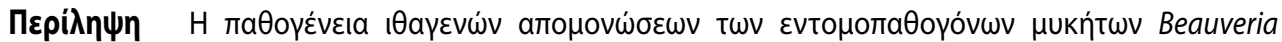

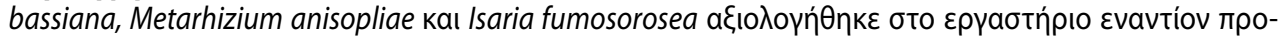

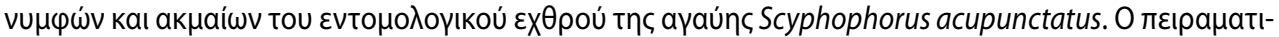

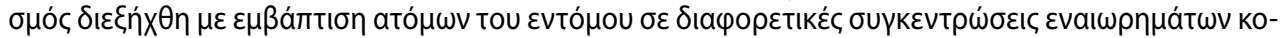

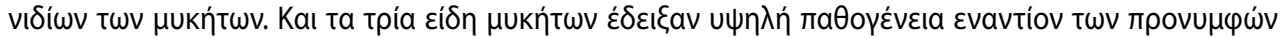

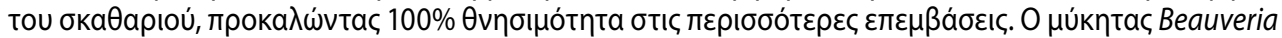

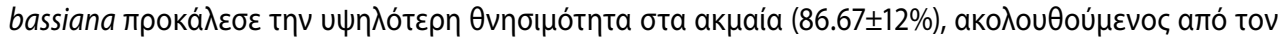

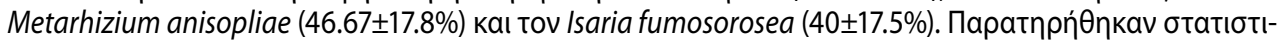

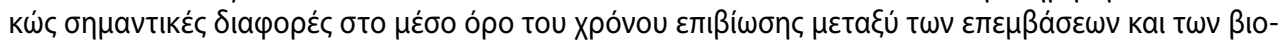

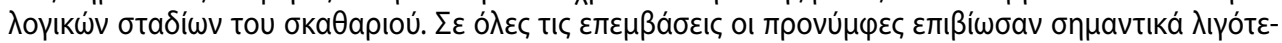

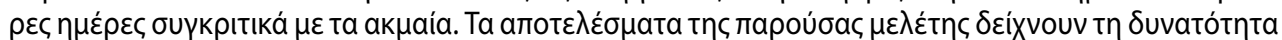

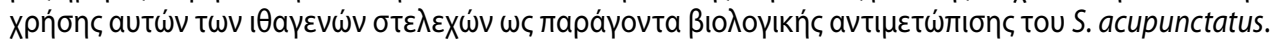

Hellenic Plant Protection Journal 8: 46-54, 2015

(c) Benaki Phytopathological Institute 